\title{
INFLUENCE OF FEAR OF FALL ON SPATIAL AND TEMPORAL PARAMETERS OF GAIT IN COMMUNITY-DWELLING ELDERLY
}

\author{
Priti Nisheet Agni ${ }^{* 1}$, Riddhi Naresh Doshi ${ }^{2}$. \\ ${ }^{{ }^{*} 1}$ Assistant Professor, K.J. Somaiya College of Physiotherapy, Ayurvihar, Eastern Express Highway, \\ Sion. Mumbai, India. \\ ${ }^{2}$ Intern, K.J. Somaiya College of Physiotherapy, Ayurvihar, Eastern Express Highway, Sion. Mumbai, \\ India.
}

\section{ABSTRACT}

Background: Aging is a gradual deterioration of physiological function.It is a multidimensional process involving various systems of the body. Out of the various problems faced by the geriatric age group "falls" are one of the major problems faced by the elderly.Fear of fall and associated avoidance of activity may lead to functional decline, restriction of social participation and hence affection of quality of life.This fear can also affect the gait pattern of an individual.Therefore the purpose of this study was to find out the influence of fear of fall on the spatial and temporal gait parameters in elderly.

Materials and Methods: 100 community dwelling elderly were made to walk 10 meters and their gait parameters were noted.The participants were classified into fearful and fearless groups on the basis of the MFES, before the test.

Result: The statistical analysis of the study was done using the mann-whitney test and a significant difference was found between the gait parameters of the fearless and fearful group.

Conclusion: There is an influence of fear of fall on the gait parameters of elderly. Fearful participants were shown to have a significantly slower gait speed,shorter stride length and step length,lesser cadence and increased stride width when compared to fearless participants.

KEY WORDS: Fear of falling, Gait, Spatial parameters, Temporal parameters.

Address for correspondence: Dr. Priti Nisheet Agni, Assistant Professor, K.J. Somaiya College of Physiotherapy, Ayurvihar, Eastern Express Highway, Sion, Mumbai, Maharashtra, India.

E-Mail: pritikulkarni2002@yahoo.co.uk

\section{Access this Article online}

Quick Response code

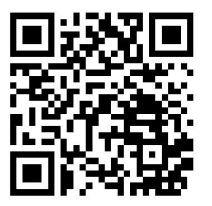

DOI: $10.16965 /$ ijpr.2017.190
International Journal of Physiotherapy and Research

ISSN 2321- 1822

www.ijmhr.org/ijpr.html

Received: 19-06-2017

Peer Review: 19-06-2017

Revised: None
Accepted: 18-07-2017

Published (0): 11-08-2017

Published (P): 11-08-2017

\section{INTRODUCTION}

Aging is a time-related deterioration of the physiological functions necessary for survival and fertility [1]. Physiological changes occur with aging in all organ systems. In older adults, functional fitness is determined by the ability to perform activities of daily living[3] and declines approximately $2.7 \%$ per year [2].

Currently $50 \%$ of the older adults report at least one functional limitation resulting in reduced quality of life [2], increased entry into long-term care facilities, and increased risk of falls.

Falls are the major cause of injury-related death in the elderly, and can lead to substantial morbidity [4]. Falls continue to be a major concern among older persons and clinicians who care for them. One in 3 adults aged 65 years or older falls [5], with $20 \%$ to $30 \%$ of these individuals suffering moderate to severe injuries[6]. Even if individuals are uninjured from a fall, between 
$3 \%$ and $85 \%$ of them develop a fear of falling or loss in balance confidence [7].

The Effective Health Care Bulletin classified the causes into five major categories: environmental (e.g. loose carpets, bathtub without rails, poor lighting, unsafe stairs, ill-fitting shoes), medication (e.g. antidepressants, sedatives and hypnotics), medical conditions and changes associated with ageing (e.g. poor vision, cognitive impairment), nutritional (e.g. calcium and vitamin D deficiency) and lack of exercise [8]. Fear of falling can precede or result from falls, and has long been recognized as a distinct health outcome even more prevalent than falling itself [9]. Tinetti and Powell defined fear of falling as "a lasting concern about falling that leads to an individual avoiding activities that he/ she remains capable of performing"[10]. Fear has been shown to affect aspects of people's mental and social lives. Bandura's theory of selfefficacy [15], which is supported by the findings of Tinetti and colleagues[10], postulates that a person's perceived capability or level of confidence determines performance of an activity, as well as true capability. According to Walker and Howland, fear of falling can compromise quality of life among elderly persons by diminishing the sense of well being, limiting mobility, and reducing social interaction. Fear of falling becomes a risk factor for falls due to decreased movement and reduced physical conditioning [11]. Walker and Howland reported that fear of falling appeared to contribute to reduced activity independent of other risk factors. According to several studies, falling and fear of falling are highly correlated [10-12]. Fear of falling can also affect the gait parameters of a person $[13,14]$.

Changes in the spatial and temporal parameters have been reported as early as the age of 60 . Studies have reported that increasing age is associated with decreased stride length and speed and increased stride width and double limb support time. However other studies contradict this, reporting that aging is not the primary factor for decline in gait parameters.

The idea that fear of falling can lead to restriction of activity emphasizes the need to study the effects of such fear on elderly persons, independent of a history of falls. The purpose of this study was to determine if fear of falling in elderly persons is associated with changes in spatial parameters like stride length and stride width and temporal parameters like cadence and speed.

\section{MATERIALS AND METHODS}

Hundred community dwelling elderly in the age group of 60-90 years were selected using convenient sampling. It was a co-relational type of study.

Participants who were able to follow instructions and complete a verbal survey related to their confidence level, stand unaided and walk 20 meters without any assistive device were included in the study. Participants with any lower extremity surgeries, limb length discrepancy and painful arthritic conditions were excluded from the study.

Outcome measures: Prior to the gait analysis the participants were asked to complete the Modified Falls Efficacy Scale [22] (MFES).

The participants were assigned into fearless and fearful groups on the basis of the MFES.

Score of eight and above was grouped as Fearless group and below 8 score was grouped as Fearful group.

Start and stop lines were placed with a distance to 10 meters in between. The participants were asked to dip feet in a tray filled with water and were made to walk a distance of 10 meters.The participants were requested to walk at their normal pace.The stride length, step length, stride width, cadence and speed were calculated.

\section{RESULTS}

Participants were divided into two categories i.e fearless and fearful on the basis of the MFES, based on the results, 67 out of 100 were in the fearless category and 33 were in the fearful category (Table-2).The statistical analysis of the data collected was carried out using Graph Pad prism 7 and the data was further analysed using the Mann-Whitney test.

Table 1: Demographic distribution of the participants.

\begin{tabular}{|c|c|c|c|}
\hline Sex & $60-70$ years & $71-80$ years & $81-90$ years \\
\hline Females & 21 & 15 & 4 \\
\hline Males & 29 & 24 & 7 \\
\hline
\end{tabular}


Table 2: Distribution according to Modified falls efficacy scale.

\begin{tabular}{|c|c|}
\hline Fearless & Fearful \\
\hline 67 & 33 \\
\hline
\end{tabular}

Stride length: The group mean scores with standard deviations for stride length were $72.02+11.5 \mathrm{~cm}$. and $65.24+4.45 \mathrm{~cm}$. for fearless and fearful groups respectively.The difference in the two group means was statistically significant( $p$ value-0.0009).

Step length: The group mean scores with standard deviations for step length were $36.10+5.8 \mathrm{~cm}$. and $32.69+2.43 \mathrm{~cm}$. for fearless and fearful groups respectively. The difference in the two group means was statistically significant ( $p$ value-0.0013).

Stride width: The group mean scores with standard deviations for stride width were $7.76+2.09 \mathrm{~cm}$. and $8.90+1.80 \mathrm{~cm}$. for fearless and fearful groups respectively. The difference in the two group means was statistically significant ( $p$ value-0.083).

Cadence: The group mean scores with standard deviations for cadence were $92.5+9.78$ and $70.72+10.3$ for fearless and fearful groups respectively. The difference in the two group means was statistically significant ( $p$ value0.0001).

Gait Speed: The group mean scores with standard deviations for gait speed were $1.41+0.13 \mathrm{~m} /$ sec. and $1.06+0.12 \mathrm{~m} / \mathrm{sec}$. for fearless and fearful groups respectively. The difference in the two group means was statistically significant ( $p$ value-0.0001).

Table 3: Group means and Standard Deviations.

\begin{tabular}{|c|c|c|c|c|c|}
\hline Groups & Stride length & Step length & Stride width & Cadence & Speed \\
\hline Fearless & $72.02+11.5$ & $36.10+5.8$ & $7.76+2.09$ & $92.5+9.78$ & $1.41+0.13$ \\
\hline Fearful & $65.24+4.45$ & $32.69+2.43$ & $8.90+1.80$ & $70.72+10.3$ & $1.06+0.12$ \\
\hline
\end{tabular}

\section{Graph 1:}

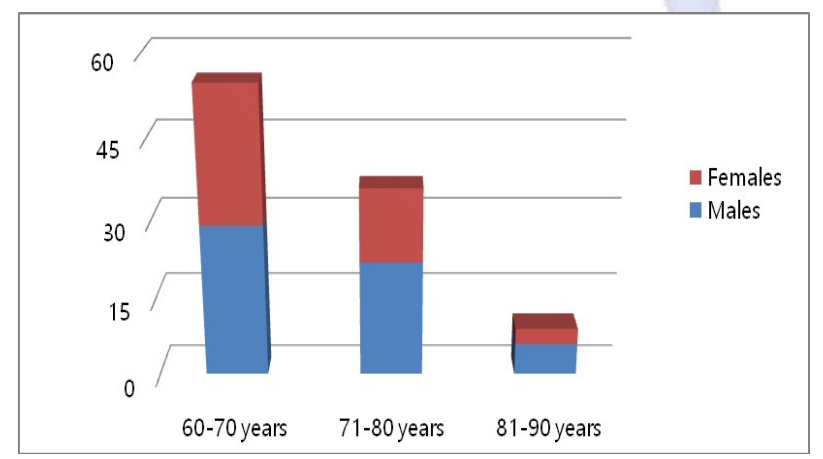

\section{Graph 2:}

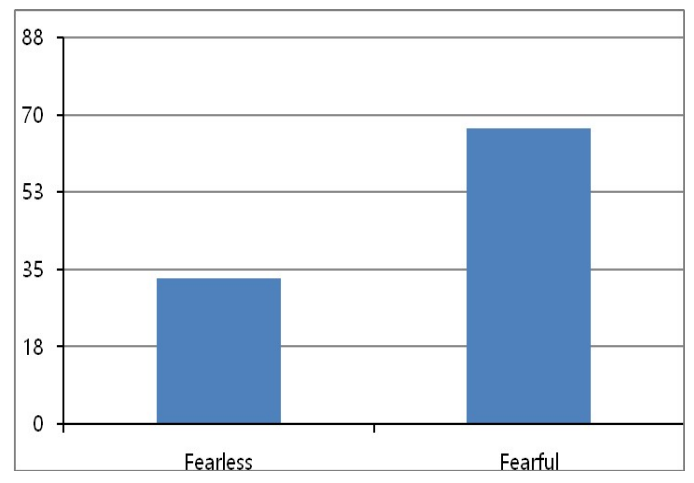

Graph 3:

\section{Stride length}

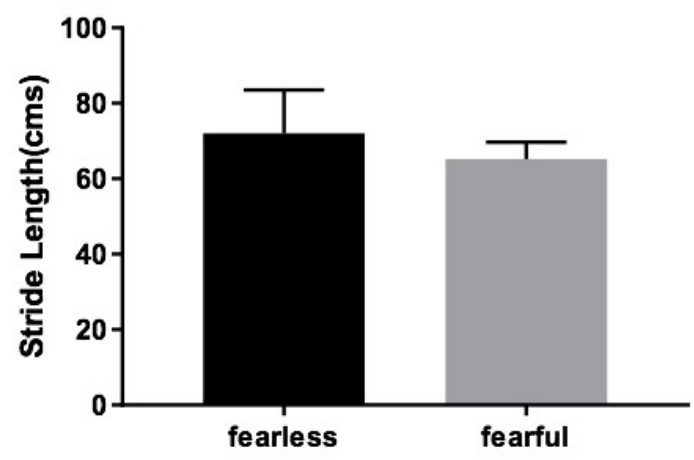

Graph 4:

Step length

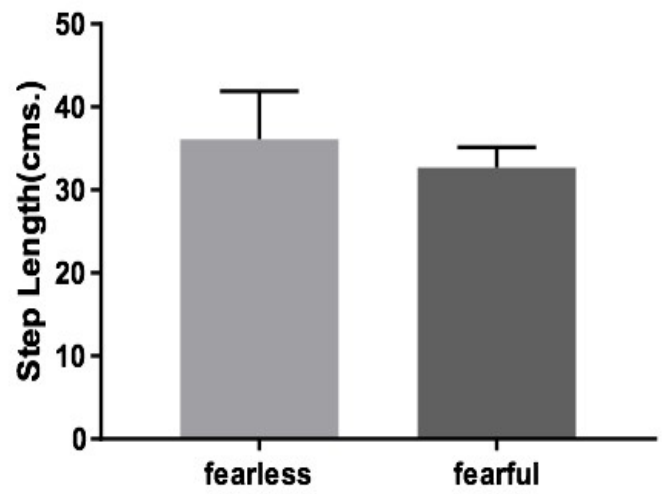

Graph 5:

stride width

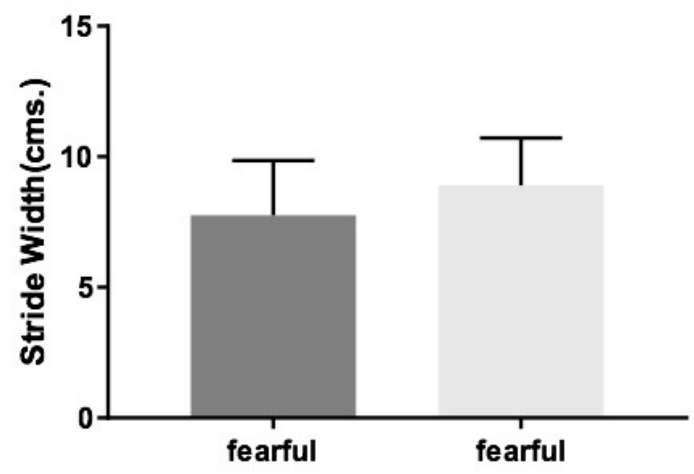


Graph 6:

Cadence

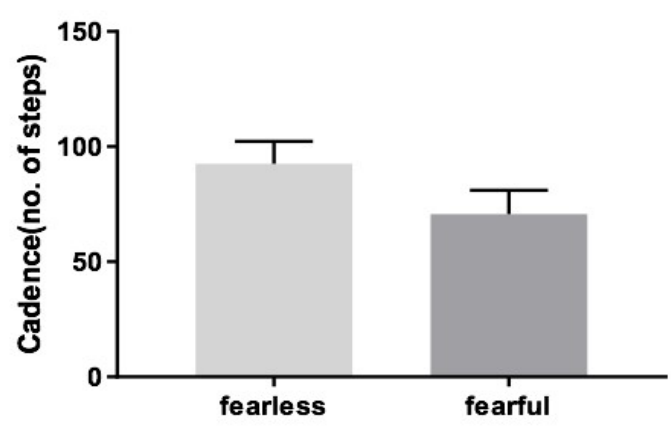

Graph 7:

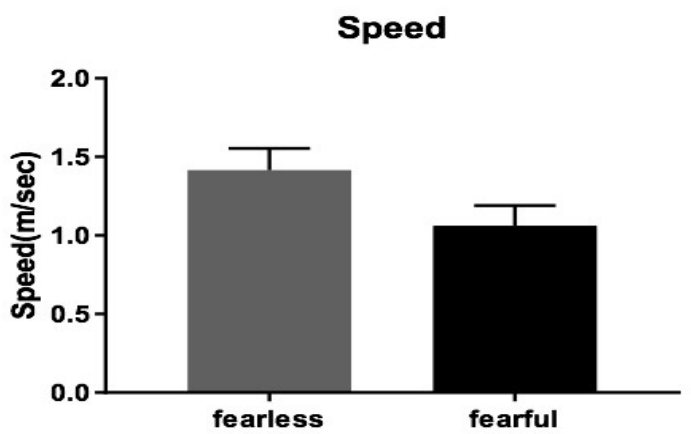

Fig. 1: Showing the measurement of Stride length.

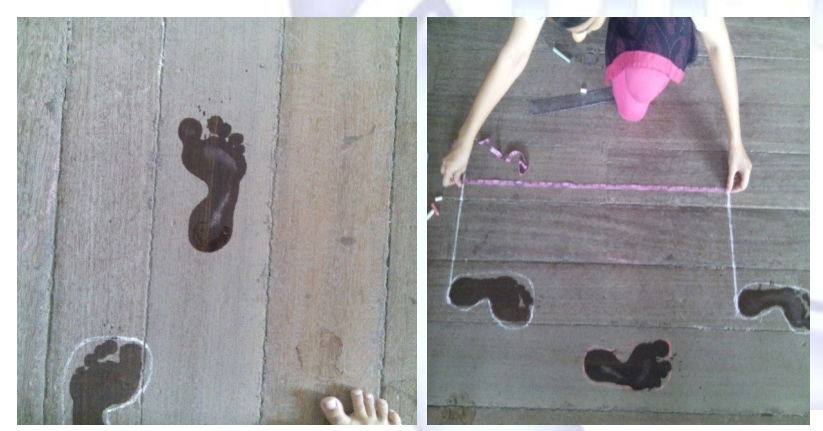

Fig. 2: Showing the measurement of Stride width.
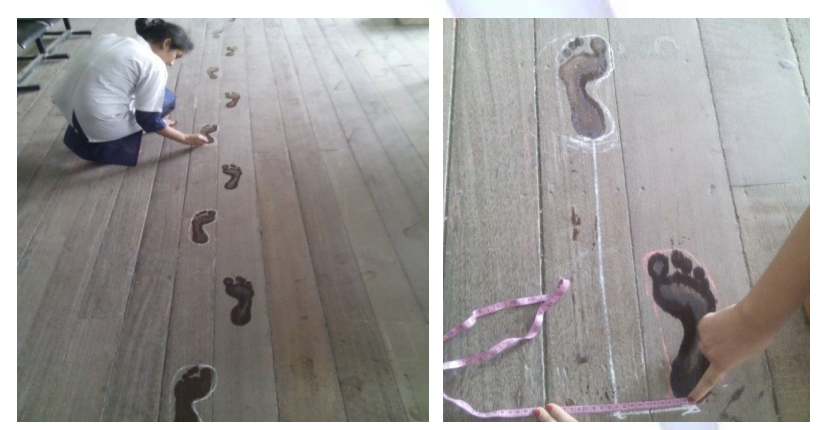

\section{DISCUSSION}

This study was done to see the influence of fear of fall on the gait parameters in communitydwelling elderly. Out of a total of 100 subjects, 67 were in the fearless group and 33 were in the fearful group(Table-2). There were 39 males and 28 females in the fearless group and 17 males and 16 females in the fearful group.
The fearful group had significantly lower stride length and step length than the fearless group (Graph-3,4).Our findings are similar to that of Maki who found that a decrease in stride length is significantly associated with such fear[13]. A person with fear of falling takes shorter steps in order to maintain the limits of stability.A shorter step and stride length is shown to be attributed with reduced limits of stability and decreased vertical movement of the center of gravity[19]. The ability to control intentional movements of the center of gravity (COG) is critical for the successful performance of various functional tasks associated with activities of daily living (ADLs) [16].

In gait, the base of support has been defined as the horizontal stride width during the doublesupport phase when both feet are in contact with the ground and the body center of gravity (CG) remains within the BOS [17]. The fearful group had significantly higher stride width than the fearless group (Graph-5). A person having pre-existing fear of fall will walk with a wider base of support and hence will have an increased stride width. A wide base of support (BOS) has been believed to be a hallmark of unsteady gait [18].

Cadence is the rate at which a person walks expressed in terms of steps per minute. The fearful group had significantly lower cadence than the fearless group (Graph-6).They walk with a slower speed in order to maintain balance and hence their number of steps per minute (cadence) also reduces.

Gait speed is a clinical marker and an important measure of functional capacity among the elderly. The fearful group had significantly lower gait speed than the fearless group (Graph7).Slow gait speed among older adults shows that they use a conscious strategy for a safer gait [20].

The results of this study supporting the hypothesis that fear of falling influences spatial and temporal parameters of gait. Shorter stride and step length, wider stride width, slower gait speed and decreased cadence were found to be associated with pre-existing fear of falling.

Our study findings were similar to Melissa $E$ Chamberlin [23], wherein the stride length, stride 
width, double limb support time and speed were calculated and a significant difference was found in the gait parameters of the two groups.

Tinetti and Powell [10] noted that a persons who has low confidence in performing certain activities in their daily living, tends to avoid them. The MFES that we used in our study had activities similar to those performed in our daily living and hence fear of fall became less subjective as the participants could closely relate to those activities.

Vellas and colleagues[21] found that more women than men reported a fear of falling after experiencing atleast one fall.In contrast to this, in our study there was no difference in the presence of fear of fall with respect to gender. One of the main limitation when studying fear of falling is that the gait parameters were assessed manually and not on GAITRite electronic system and hence there are chances of human error. Other limitation while assessing fear of falling was that some elders might be reluctant to admit their fear.The MFES has been found to be valid and reliable for assessing fear of falling[22].However, the biggest challenge was to explain the MFES to the participants. Also some activities in the MFES eg. light gardening might not be normally performed by the person or activities like preparing a simple meal may be gender specific and hence difficult to answer. It has been suggested that the adaptations that individuals make in their gait patterns secondary to a fear of falling are used to reduce the risk of falling[13].A suggestion for future studies is to find out treatment strategies to improve the quality of life of people who have fear of falling. The results of this study show promise for future clinical use. Physical therapists that see elderly patients having any gait deviations can consider fear of falling as a reason and can rehabilitate them to resume a more functional gait pattern.

\section{CONCLUSION}

This study found a statistically significant difference between fearful and fearless groups in spatial and temporal gait parameters for community dwelling elderly. Fearful participants were shown to have a significantly slower gait speed, shorter stride length and step length, lesser cadence and increased stride width when compared to fearless participants. Measuring the gait parameters are a vital part of clinical evaluation. Therefore, it is important to transfer this knowledge to the clinical setting and address fear of falling as a contributing factor in elderly patients who show gait abnormalities and hence strive to improve the quality of life and achieve the highest level of functioning for all patients.

\section{Conflicts of interest: None}

\section{REFERENCES}

[1]. Scott.F.Gillbert,Developmental biology $6^{\text {th }}$ edition.

[2]. Runge M,Rittweger J,Russo CR. Is muscle power output a key factor in age related decline in physical performance?A comparison of muscle cross section, chair raising test, and jumping power. Clin Physiol Funct Imaging,2004;24(6):335-340.

[3]. Arthritis Division, Department of Medicine, University of California, San Diego, School of Medicine, La Jolla, California Senior Fitness Test Manual,Rikli RE,Jones CJ,Human Kinetics,2001.

[4]. Fatalities and injuries from falls among older adultsUnited States, 1993-2003 and 2001-2005, Centers for Disease Control and Prevention (CDC),MMWR Morb Mortal Wkly Rep. 2006; Nov 17; 55(45):12214.

[5]. Hausdorff JM,Rios DA, Edelberg HK. Gait variability and fall risk in community living older adults. Arch Phys Med Reahbil. 2001;82(8):1050-1056.

[6]. Alexander BH, Rivara FP, Wolf ME. The cost and frequency of hospitalization for fall-related injuries in older adults. Am J Public Health,1992;82(7): 1020-1023.

[7]. Scheffer AC, Schuurmans MJ, Van Dijk et al., Fear of falling:measurement strategy, prevelance, risk factors and consequences among older persons. Age aging 2008;37(1):19-24.

[8]. Nuffield Institute for Health, University of Leeds and NHS Centre for Reviews and Dissemination. Preventing falls and subsequent injury in older people. Effective Healthcare 1996;2(4):1-16.

[9]. Legters K. Fear of falling. Phys Ther. 2002 Mar; 82(3):264-72

[10]. Tinetti M, Powell L. Fear of falling and low selfefficacy:a cause of dependence in elderly persons. J Gerontology. 1993;48:35-38.

[11]. Walker JE, Howland J. Falls and fear of falling among elderly persons living in the community: occupational therapy interventions. Am J Occup Ther. 1991;45:119-122.

[12]. Arfken CL, Lach HW, Birge SJ, Miller JP. The prevalence and correlates of fear of falling in elderly persons living in the community. Am J Public Health. 1994;84:565-570. 

DWELLING ELDERLY.

[13]. Maki B. Gait changes in older adults: predictors of falls or indicators of fear? J Am Geriatr Soc. 1997;45:313-320.

[14]. Nelson A, Certo L, Lembo L et al. The functional ambulation performance of elderly fallers and nonfallers walking at their preferred velocity. Neuro Rehabilitation,1999;13:141-146.

[15]. Bandura A. Self-efficacy mechanism in human agency. Am Psychol. 1982;16:122-147

[16]. Sean Clark, PhD, Debra J. Rose, PhDM. Evaluation of dynamic balance among community-dwelling older adult fallers, Gordon College, California State University, april-2001

[17]. Krebs DE, Goldvasser D, Lockert JD, Portney LG, GillBody KM. Is base of support greater in unsteady gait? Phys Ther. 2002 Feb;82(2):138-47.

[18]. Nutt JG, Marsden CD, Thompson PD. Human walking and higher-level gait disorders, particularly in the elderly. Neurology.1993;43:268-279.

[19]. Anne Shumway-Cook, Marjorie H Woollacott. Motor Control-translating research into clinics, $5^{\text {th }}$ edition;364-table:14.1
[20]. Clark RA, Bryant AL, Pua Y, McCrory P, Bennell K, Hunt M. Validity and reliability of the Nintendo Wii Balance Board for assessment of standing balance. Gait \& posture. 2010 Mar 31;31(3):307-10.

[21]. Vellas BJ, Wayne SJ, Fear of falling and restriction of mobility in elderly fallers. Age Ageing.1997;384392

[22]. Hill KD, Schwarz JA, Kalogeropoulos A, Gibson S. Fear of falling revisited. Arch Phys Med Rehabilitation 1996;1025-1029

[23]. Melissa E chamberlin, brandy D fulwider,sheryl sanders. Does fear of fall influence the gait parameters in elderly. School of PT, pacific university, oregon, 2005

How to cite this article:

Priti Nisheet Agni, Riddhi Naresh Doshi. INFLUENCE OF FEAR OF FALL ON SPATIAL AND TEMPORAL PARAMETERS OF GAIT IN COMMUNITY-DWELLING ELDERLY. Int J Physiother Res 2017;5(4):2276-2281. DOI: 10.16965/ ijpr.2017.190 